\title{
REVIEW
}

\section{Extinction of microbes: evidence and potential consequences}

\author{
Markus G. Weinbauer*, Fereidoun Rassoulzadegan \\ Microbial Ecology \& Biogeochemistry Group, Université Pierre et Marie Curie-Paris 6, Laboratoire d'Océanographie de \\ Villefranche, 06234 Villefranche-sur-Mer Cedex, France; CNRS, Laboratoire d'Oceanographie de Villefranche, 06234 \\ Villefranche-sur-Mer Cedex, France
}

\begin{abstract}
Microbes, i.e. viruses, prokaryotes, protists and fungi are main players in biogeochemical cycles in aquatic and soil systems. As predators, pathogens, commensals and symbionts they are associated with multicellular life forms. Microbes show a dazzling array of biodiversity and it has been argued that due to their small size and huge numbers, microbes are distributed worldwide ('everything is everywhere'). However, we summarize evidence that even free-living microbes have biogeographies and thus might be subject to at least local extinctions. Furthermore, some microbes do seem to be restricted to very particular environments and are endangered in as much as these environments are threatened. Finally, microbes intimately associated with other organisms share (partially) the biogeographies of their hosts. As far as they are species-specific, they could potentially become extinct along with their hosts. Overall, extinction rates typically reported are underestimates, since they do not take into account associated microorganisms which likely become extinct with the host organism, plant or animal. As multicellular species can have specific viral, prokaryotic, protistan and fungal species associated with them, extinction rates could be several times higher than assumed previously.
\end{abstract}

KEY WORDS: Virus $\cdot$ Prokaryotes $\cdot$ Protists $\cdot$ Fungi $\cdot$ Biogeography $\cdot$ Species concept Resale or republication not permitted without written consent of the publisher

\section{INTRODUCTION}

Extinction is a principle of evolution and well over $99 \%$ of the species that have ever lived have become extinct. It is often said that we lose about 1 species per day; however, this is just a guesstimate. Nevertheless, we seem at present to be living in a period of mass extinction, the 6th of its kind, in which human activity such as that which causes habitat fragmentation seems to be the driving force.

Microorganisms are not a taxonomic unit but are defined by their size and are usually only visible through a microscope. They comprise viruses, prokaryotes (the domains Bacteria and Archaea), protists and fungi. The first 3 of these groups are shown in Fig. 1. The aim of the present study was 2-fold: (1) to provide an introduction to microbes and microbial extinctions for the non-specialist and (2) to review, for microbiologists and microbial ecologists, the evidence and potential for microbial biogeographies and extinctions and their effects on ecosystems. Because of the nature of the authors' expertise, more emphasis will be placed on aquatic than on terrestrial systems.

\section{MICROBES AND THE ENVIRONMENT}

Microbes are everywhere. They are found in the ocean, in the soil, deep in the crust of the earth, in ice, in hot springs and attached to and within other organisms as pathogens, commensals and symbionts. Blood is one of the few environments where they usually do not thrive. It has been estimated that there are ca. 4 to $5 \times$ $10^{30}$ prokaryotic cells on Earth, with the open ocean, soil, and oceanic and terrestrial subsurface showing the highest abundances (Whitman et al. 1998) (Table 1). For oceanic protists, prokaryotes and viruses, respectively, abundances are related roughly as 1:1000:6250 (Wein- 


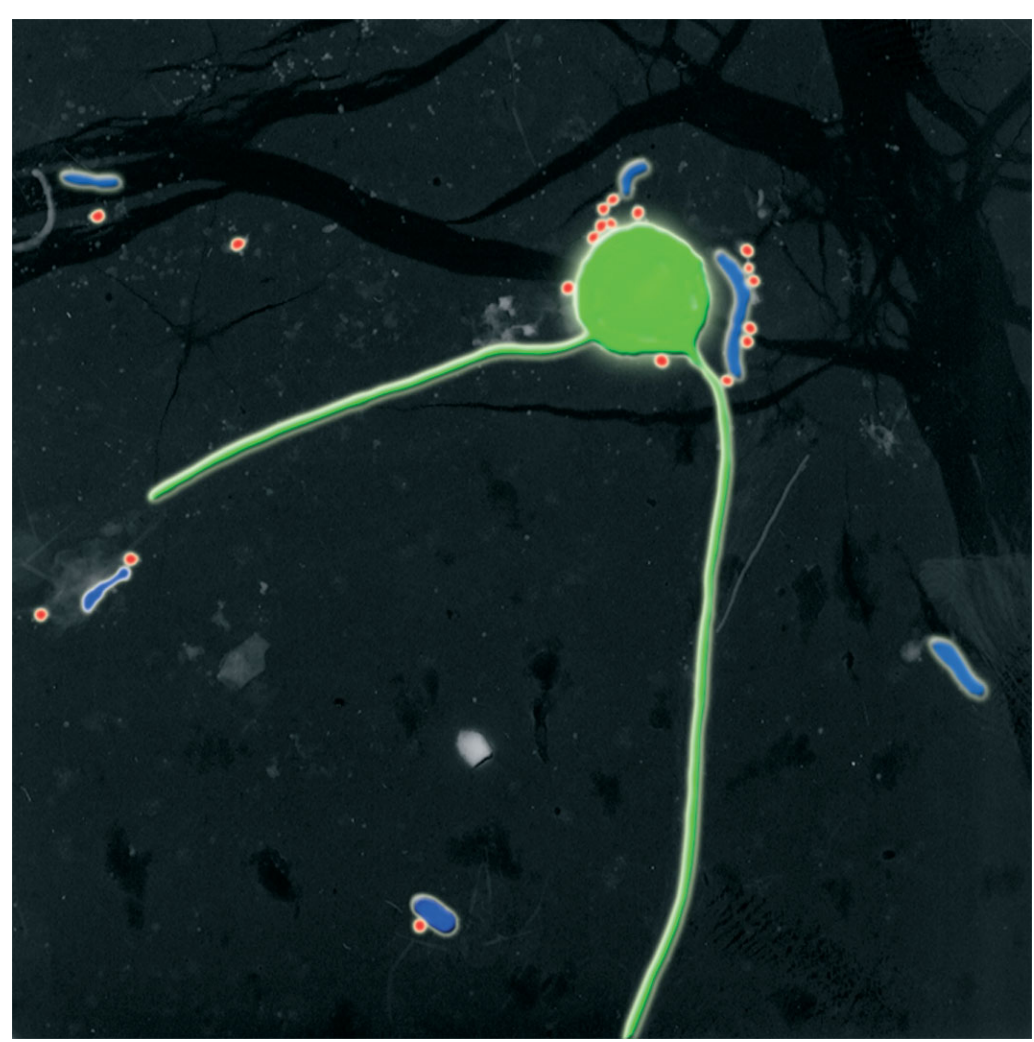

Fig. 1. False color image of microbes from a sample in the northern Adriatic Sea. Red: viruses; blue: bacteria; green: flagellate

bauer \& Herndl 2002). A typical coastal water sample contains $10^{7}$ viruses, $10^{6}$ bacteria and $10^{3}$ protists $\mathrm{ml}^{-1}$.

Microbes come in diverse forms; however, it is not known how many different species of microbes inhabit the planet. One of the reasons for this is the problems involved in defining a microbial species (for a discussion on concepts, see 'The prokaryotic species concept, horizontal gene transfer and speciation' below). Another reason is the fact that the majority of prokaryotic cells cannot be easily grown in culture, which is a prerequisite for species identification of microbes. Only about 5000 to 6000 prokaryotic species have been formally described. Cultivation-independent methods have been developed to study prokaryotic species richness; however, there is some uncertainty about the res-

Table 1. Estimates of total abundances of microorganisms in the oceans and in soil (Whitman et al. 1998, Weinbauer \& Herndl 2002, Suttle 2005)

\begin{tabular}{|lcc|}
\hline Microorganism & Ocean & Soil \\
\hline Prokaryotes & $10^{29}$ & $10^{29}$ \\
Viruses & $10^{30}$ & $10^{28}$ \\
Protists & $10^{26}$ & $10^{26}$ \\
\hline
\end{tabular}

olution of these methods. In soil, it has been estimated that there are up to 10000 species $\mathrm{g}^{-1}$ (Torsvik et al. 1990). About 30000 bacteria and archaeal species are represented in GenBank (based on sequence information). At least 1800 species and 1.2 million new genes were found using a shotgun sequencing approach of microorganisms from a single sample in the Sargasso Sea (Venter et al. 2004) and 643 new species were identified using a $99 \%$ similarity as delineation between prokaryotic phylotypes or species based on 16S rRNA gene sequences (Venter et al. 2004). This suggests high species diversity and biodiversity in the ocean. However, the use of a new approach (454 sequencing) on deep water samples of the Atlantic and Pacific Oceans has led to the suggestion that previously published data underestimate diversity, probably by an order of magnitude (Sogin et al. 2006). In addition, rarefaction curves suggest that additional sampling (i.e. sequencing) will strongly increase the estimates of bacterial diversity.

In 1001 water samples from a coastal environment, up to 7000 viral types have been detected using a metagenomics (community genomics) approach and it is believed that viruses represent the largest unknown sequence space (Breitbart et al. 2002). Many microbial pathogens are species-specific and many hosts have more than one specific pathogen. Moreover, these pathogens are hosts to other pathogens or predators such as viruses, which might increase diversity considerably. Overall, the variety of microbial life forms is astounding.

Prokaryotic microbes are the 'movers and shakers' of the biosphere. They invented photosynthesis long before eukaryotes evolved, and their oxygen production changed the atmosphere to the oxygenic status we are currently experiencing. Microorganisms degrade and remineralize organic material, others produce methane, reduce sulfate to sulfide, integrate molecular nitrogen or change the forms of inorganic nitrogen. Microorganisms drive the global cycles of carbon, nitrogen, phosphorus and sulfur. Without microorganisms all other life forms would not survive.

Symbioses of multicellular organisms with microorganisms have had great evolutionary success. For example, there are about 15000 species of lichens, which are a symbiosis between fungi and green algae or cyanobacteria (or both). Lichens can even exist in the water-depleted deserts of Antarctica. In mycorrhiza, the 
symbiosis between plant roots and fungi, the fungus recycles nutrients for the plant, while the plant provides organic matter for the fungi. This symbiosis exists in the vast majority of terrestrial plants and might have been the reason for the spread of plants on the continents. Another type of symbiosis resulted in the largest structures made by organisms on Earth, the coral reefs. This was made possible by the alliance between coral hosts and a photosynthetic dinoflagellate (zooxanthellae in which the coral host obtains sugars from the algae and the interference of algae with carbon cycling enhances calcification. This symbiosis is one of the reasons why coral reefs, one of the most diverse ecosystems, can exist in the nutrient-poor 'blue deserts' of the ocean.

Prokaryotes exchange genes, and this horizontal gene transfer is sometimes referred to as microbial sex. Viruses can also transfer genetic material between cells and there is increasing evidence that they played a major role in the evolution of large taxonomic groups such as algae or mammals (Villarreal \& DeFilippis 2000, Villarreal et al. 2000). Indeed, such 'Virio-Darwinism' might explain evolutionary changes and inventions which would be hard to explain otherwise (Weinbauer \& Rassoulzadegan 2004). The viral and prokaryotic 'kamasutra' is certainly an under-evaluated driving force in evolution. Finally, organelles such as plastids or mitochondria arose from prokaryotes that established symbiotic relationships with other cells (endosymbiont theory).

The relative simplicity of microbes, and particularly phages, has enabled scientists to discover basic principles of life, such as the finding that DNA is the hereditary molecule and the detection of DNA replication mechanisms. Phages were an essential basis for the advance of the discipline of molecular biology (Duckworth 1987). A similar development appears to be taking place now, as microorganisms are used to decipher the structure and functioning of genomes. Other benefits of current advances in knowledge are the microbial enzymes used in industry and medicine; rather than trying to synthesize such enzymes in vitro, scientists now look for them in microbes. Also, microorganisms are increasingly used to deal with pollution, for example in contaminated soils. Old forms of microbial biotechnology are essential to the production of dairy produce, beer and wine.

\section{THE PROKARYOTIC SPECIES CONCEPT, HORIZONTAL GENE TRANSFER AND SPECIATION}

The prokaryotic species is often defined by a $70 \%$ DNA-DNA hybridization level frequently corresponding to a $97 \%$ (sometimes $99 \%$ ) level of sequence similarity of the $16 \mathrm{~S}$ rRNA gene and on a metabolic charac- terization of the isolates (for a summary of concepts see (Rossello-Mora \& Amann 2001). This concept has, however, been strongly attacked. For example, it has been argued that swapping of genes among species by horizontal gene transfer could make a universal classification based on phylogenetic reconstructions impossible (Doolittle 1999, Martin 1999) and might 'shake the tree of life' (Pennisi 1998). A species concept also exists for viruses (Regenmortel 1992); gene transfer here, however, is even more of a problem than for prokaryotes. For example, even for the monophyletic group of the tailed phages (such as the textbook phages T4 and $\lambda$ ), no common gene exists (Hendrix et al. 2000). However, it has been pointed out that there are at least 22 different species definitions for eukaryotes (Rossello-Mora \& Amann 2001), a fact which indicates general problems with the species concept.

Since most microbes have not been (or cannot be) cultivated, they are detected in the environment by various RNA- and DNA-based techniques such as 16S rRNA gene and internally transcribed spacer (ITS) region approaches or multilocus sequence typing. The prokaryotes belonging to such delineations are often called phylotypes, genotypes or ecotypes, depending on the phylogenetic resolution, since these techniques alone are not sufficient for a species description (Rossello-Mora \& Amann 2001). However, as pointed out by Hughes et al. (2001) the methods used by microbial ecologists to assess diversity are often as precise as those used by macroecologists. This is probably even more significant in paleobotany and paleozoology, where species definitions are often based on skeletons, fossilization of soft body parts and negative prints in sediments or coal. Yet, such definitions are used to document extinctions and changes in diversity of plants and animals on a geological time scale. The available methods for microbes have been useful in in situ and experimental ecological studies, for example in revealing life style concepts (Pernthaler 2005, Pernthaler \& Amann 2005) or testing ecological theory (Bell et al. 2005). Therefore, although the level of taxonomic resolution cannot always be clearly determined, the methods seem to be precise enough to raise the question of microbial extinctions.

It has been argued that gene exchange within bacterial species slows down diversification by increasing genetic similarity, whereas gene transfer among species increases diversity, e.g. by opening new niches (Torsvik et al. 2002). However, gene exchange can also help to sustain co-existence of genetically different ecotypes (Cohan 2001). Adaptive mutations in one ecotype (e.g. the ability to use new resources) might threaten another ecotype by invading its niche. Gene exchange would help protect ecotypes from extinction if the adaptive mutation can be transferred. Since the 
ecotypes would then share the adaptive mutation, they would not extinguish each other, but continue to exist as separate types, and therefore the specific genes for both ecotypes would be preserved.

Cohan (2001) argued that speciation is less constraining for bacteria than for eukaryotes, since promiscuity of genetic exchange is less frequent in the former. This means that the strong recombination in sexual organisms is an obstacle to diversification, whereas the recombination in bacteria by gene transfer is much lower and thus diversification is easier. Therefore, the speciation rates should be much greater for bacteria than for eukaryotes.

\section{BIOGEOGRAPHY OF MICROBES}

It has been argued that there are no distributional barriers for small free-living organisms such as microbes (Finlay \& Fenchel 1999). The concept that global species diversity is inversely related to body size (Finlay et al. 1996) suggests that the shear number of protists makes global dispersal very likely by mechanisms such as hurricanes, ocean circulations, groundwater connections, damp fur, etc. As prokaryotes are about 3 orders of magnitude more abundant than protists (at least in aquatic systems) (Table 1), prokaryotes should be even more easily transmitted. Consequently, the large number of microbial cells per species makes extinction unlikely, e.g. due to demographic stochasticity (Cohan 2001). Indeed, if 'everything is everywhere', but, 'the environment selects' (de Wit \& Bouvier 2006) (cosmopolitan hypothesis), extinction is not a threat. In its most explicit form, this concept assumes that, at least for free-living microorganisms, all diversity (in terms of richness) is contained in a single sample. Fenchel (2005) recently insisted that the cosmopolitan hypothesis is correct.

This view has been heavily criticized and no consensus has been reached. The criticism can be roughly divided into 2 groups. The first one stresses that the concept is wrong and the second claims that the concept might be correct but has distracted attention from the important question of microbial biogeography. A detailed discussion of what Baas Becking and Beijerinck really said (de Wit \& Bouvier 2006) makes it clear that the cosmopolitan hypothesis - at least originally - did not disregard the biogeography of freeliving microorganisms. However, it also becomes clear that the original hypothesis might be difficult to prove because of detection limits of rare microbes. Approaches such as the use of sensitive PCR technology to detect forms presently thought to have restricted distributions (e.g. searching for hydrothermal vent microbes in polar sea ice or trying to enrich these microbes by converting sea ice to hydrothermal vent conditions), may be able to solve the problem. However, only if the target organisms can be detected will the debate be resolved, since a negative result of such analyses would not prove that the microbes were not there. In the present study, evidence is presented that biogeographies do exist for free-living microbes, a fact which has not previously been sufficiently appreciated. This evidence does not mean that endemicity occurs in all species.

Cho \& Tiedje (2000) isolated fluorescent Pseudomonas strains from soils from 4 continents, and using rep-PCR genomic fingerprinting with BOX primers they found 85 unique genotypes which did not overlap between sites or continents. This endemism could be further specified, since the degree of dissimilarity was related to the geographic distance between the sites of origin of the isolates. These data suggest a high degree of endemicity and that geographic isolation played a significant role in the diversification of Pseudomonas. Using a similar genetic fingerprint, Oda et al. (2003) showed for the purple nonsulfur bacterium Rhodopseudomonas palustris isolated from freshwater marshes in the Netherlands that the degree of dissimilarity increased with the distance of the locations. Another example of geographic barriers has been presented for the hyperthermophilic archaeon Sulfolobus (Whitaker et al. 2003). Sulfolobus was isolated from water and sediments of geothermal hot springs in Eastern Russia, Iceland and North America from a nested hierarchy of geographic locations. High-resolution multiloci sequence analysis revealed geographically distinct clades which were independent of the characteristics of the spring. These data suggest that the gene flow among Sulfolobus populations is limited. Data on the importance of physical isolation for prokaryotic diversification have recently been summarized (Papke \& Ward 2004).

For protists, the debate on the cosmopolitan hypothesis is based on morphospecies, i.e. morphologically identical protists, which have world-wide distribution. It has been suggested that variation in rRNA gene sequences reflects accumulation of neutral mutations and, thus, genetic divergence (cryptic species) does not necessarily mean functional diversity (Fenchel 2005). However, studies have demonstrated that these morphospecies can be genetically divergent. For example, morphospecies of the ciliate genera Halteria/Meseres and Strombidium (Katz et al. 2005) were found to be composed of several distinct genetic clades based on ITS loci. This has been related to the ephemeral nature of the habitats (lakes and ponds for Halteria/Meseres and tidal pools for Strombidium), which allowed diversification over geological time. When loci with putative cellular functions, which 
might be less influenced by neutral mutations, were investigated the data suggested diversity at the genomic level. The finding that the genetic diversity of ciliates was higher in ephemeral ponds and tidal pools than in the more stable coastal waters (Katz et al. 2005) suggests that the stability of the system influences diversity and diversification. Much could probably be learned about functional diversity from ecophysiological studies of isolates (Lowe et al. 2005); however, this is a time-consuming enterprise.

Besides population density, dispersal ability determines the colonization rate of a taxon (Martiny et al. 2006). For actively dispersed organisms, the lifespan (or time between cell divisions), which determines the dispersal capability, increases with the size of organisms. Thus, small organisms have a small dispersal capacity and spread by active propulsion. However, this does not prevent them from spreading over wide distances. Nevertheless, as Martiny et al. (2006) have pointed out, a genetic divergence (diversification or even speciation) could occur compared to the source population and create a biogeographic structure. This is also true for organisms with a passive dispersal mode, e.g. plankton, where no relationship between body size and lifetime is assumed. Microbial cells in deep soils, sediments and the subsurface will have a smaller dispersal rate than cells in water or surface soils and this should even increase the development of biogeographic patterns.

The number of studies on microbial biogeography has increased dramatically over the past few years. For example, a Theme Section in Vol. 41(1) of Aquatic Microbial Ecology (2005) was devoted to this topic. Clearly, 'not all taxa are everywhere in significant quantities' (Dolan 2005). Terrestrial, limnetic and marine habitats, and environments such as geothermal springs or anoxic sediments harbor specific microorganisms. In the deep sea, Archaea are as abundant as Bacteria (Karner et al. 2001). The clade Roseobacter seems to be restricted to temperate and polar regions (Selje et al. 2004), although the oceanic gyres cover these areas as well. Data from isolates indicate that environmental constraints, such as temperature (cryoand thermophilic bacteria) and hydrostatic pressure (hydrophilic bacteria), also exist. This suggests that distributional constraints and biogeographies can also be expected for prokaryotic species. The finding that microbial composition is not random but changes with factors such as salinity, depth and latitude (data compiled in Martiny et al. 2006) is also an indication of microbial biogeography. However, the existence of habitat preferences instead of 'true' biogeographies (in the sense of historical contingencies as a cause of distribution patterns) cannot be fully ruled out. In a study of soils from South and North America using TRFLP fingerprinting of the 16 rRNA gene, the $\mathrm{pH}$ was found to be the most significant denominator for diversity (Fierer \& Jackson 2006). Recently, it has been shown that there is a massive diversity of a 'rare bacterial biosphere' in deep marine waters (Sogin et al. 2006). Some of the rare phylotypes can become dominant in specific water masses. These data suggest that at the community level not only physical separation but system-specific constraints influence or even control the relative abundance of phylotypes.

It has been shown along transects from estuarine to open ocean waters that phages infecting cyanobacteria (cyanophages) differed in community composition between environments (Zhong et al. 2002). In addition, some cyanophage sequences were only found in a specific depth layer, the deep chlorophyll maximum. This suggests that viruses of free-living hosts can also have biogeographies, although others such as viruses infecting the marine microalgae Micromonas pusilla are more cosmopolitan (Cottrell \& Suttle 1991). Other examples are also known (see Weinbauer 2004). It has been suggested recently that genetic divergence in marine viruses increases with geographic distance (Angly et al. 2006).

These data indicate that (1) endemicity can occur even in free-living microorganisms and (2) there is a biogeography of the abundance of some taxa (although they might be cosmopolitan). Thus, endemicity can exist despite the strong counteracting forces of dispersal and gene flow. Endemicity of microorganisms can mean potential (local) extinctions in cases where the respective environments are endangered. Cosmopolitan microbial populations, even if they are very rare in some environments, are not endangered; nevertheless, local reduction can have an effect on their genetic diversification and their effect on ecosystem functions.

More evidence of endemicity and biogeography is available for microorganisms associated with plants or animals. Hosts can be considered as islands, which permit the development of endemism in prokaryotes. For example, it has been shown that bacteria on the marine sponge Cymbastela concentrica differ between tropical and subtropical areas (Taylor et al. 2004, 2005) and thus have biogeographies. Species-specific associations between corals and bacterial communities have also been documented and many new 16S rRNA gene sequences obtained (Rohwer et al. 2001, 2002). Taxonomic differences between bacteria attached to the coral mucus and those living within the coral tissue have also been found (Bourne \& Munn 2005). Similar data have also been reported for other animals such as nematodes. In addition, parasites of animals and plants may share the biogeography of their hosts or even have biogeographies of their own, such as a smaller geographical range than their hosts. For example, 
phages infecting Halobacterium cannot infect their host at high salinities, and the infectious biogeography of these phages is different from the niche of the host (summarized in Weinbauer 2004).

Degrading whales provide substrate to a diverse community including microorganisms which are related to lipid degraders (Goffredi et al. 2005). These sulfur-reducing bacteria use fats and oils within the whale bones and seem to be specific for the whale fall communities. In addition, there are chemosynthetic bacterial endosymbionts associated with the invertebrates. This provides evidence that specific prokaryotic communities are not only associated with living but also with decaying animals. Local extinctions have likely occurred for these species, since some of the old migration routes or populations of whales no longer exist; the grey whale population in the North Atlantic, for example, became extinct about 300 years ago.

\section{EVIDENCE OF ENDANGERED MICROBES}

Exobiology expresses an example of perhaps unexpected concern for microorganisms, in that human activity on Mars might endanger life forms there (given there is life on Mars). These microbes can be regarded as potentially endangered (if they exist). Local extinctions (or strong reductions in the abundance of microbial species) probably occur quite frequently, e.g. due to clearing of forests, agricultural activity or erupting volcanoes.

All multicellular organisms investigated in some detail contain pathogens, commensals or symbionts and are populated by a diverse prokaryotic community. These prokaryotes harbor pathogens themselves and are also subject to predators. Thus, a multicellular organism is best regarded as an association of species - a mini-ecosystem - and many of these species exist only in this association. For corals, it has been argued that changes in associated microbes allow for an adaptation of the mini-ecosystems to environmental changes (Reshef et al. 2006, Rosenberg et al. 2007) and this could reduce extinction rates. However, it is obvious that this association cannot prevent extinction. During extinction the entire association is lost, which multiplies the loss rates. All the specific microbes living in the hair of the mammoth or the feathers of the Dodo, all the specific microbes associated to the specific lice of these species, all their specific pathogens are extinct (unless they can be 'revived' from frozen mammoths in the tundra or from feathers in museums). If multicellular eukaryotes have specific fungal, protistan, prokaryotic and specific viral pathogens or associates, extinction rates would be several times higher than assumed without the inclusion of microorganisms.
Detection of microbial fossils is difficult compared to detection of plant and animal fossils, as the former typically produce no hard parts such as shells, and identification is often impossible as they typically have no distinct morphological features. This is one of the reasons for our lack of knowledge on extinction rates of microbes. However, stromatolites (microbial reefs) were globally distributed in the Proterozoic but the abundance decreased markedly and at present there are only a few sites left. This suggests at least local extinctions in the geological past. Also, we are only just beginning to assess the diversity of associated microorganisms. Many, if not most, habitats remain unstudied. Even for the well-studied ecosystem of human teeth, new bacteria have recently been described (Listgarten \& Loomer 2003). Because of the limited number of studies, species specificity of microbe-animal or microbe-plant associations remains largely unknown. Although some microbial pathogens or mutualists have large host ranges, the species-specificity or a narrow host range are also well known for some pathogens of humans and domestic animals and plants, and for animals and plants harvested in fisheries, agriculture and forestry.

Most free-living microbes are likely not endangered, although their local distribution might vary considerably and local extinctions (in the sense of population densities below the detection limit) might occur. However, associated species may be 'threatened' in the same way as the multicellular hosts organisms. If microbes have a distributional range smaller than that of their host, as suggested by the sponge example above, this chance may be even greater. Microbes may also become extinct when one partner in a predator-prey or parasite-host system loses the adaptation race. Viruses might be involved in the extinction of other microbes (Emiliani 1982, 1993). As long as the virus cannot find an alternative host, this means self-extinction.

\section{SHOULD WE CARE ABOUT POTENTIAL LOSSES OF MICROBIAL SPECIES?}

It has been argued that the prokaryotic DNA world constitutes a 'global superorganism' that shares the gene pool by horizontal gene transfer (Doolittle 1999), the microbial 'kamasutra'. However, the genes are not distributed evenly across prokaryotes. Thus, extinction of prokaryotic species would often mean losses not of single functions but only of specific combinations of functions in species. Losses of functions would likely only occur in very specific cases, when a function is linked to a very specific habitat such as a host. Certainly, not all microbial genes and gene combinations are crucial for 
the functioning of ecosystems, but we do not know which are dispensable. Lost genes might also represent losses for medical and biotechnological applications.

The Roseobacter clade is significantly involved in marine carbon and sulfur cycles (Mullins et al. 1995, Zubkov et al. 2001a,b). This clade is found in polar and temperate regions of the northern and southern hemisphere, but is absent in tropical and subtropical regions (Selje et al. 2004). Thus, temperature could be one of the factors restricting its distribution. Changing temperatures could severely affect the distribution of the Roseobacter clade and, thus, of carbon and sulfur cycling. While other bacteria might take over the ecosystem functions, the specific requirements of their ecological niche could cause changes in the system. This could provoke a cascade of consequences, particularly as a temperature increase would also affect other organisms. The Roseobacter clade would only become locally extinct in this scenario, but these local extinctions might lead to changes in the Roseobactermediated ecosystem functions.

Other scenarios can be envisioned. For example, microbes are abundant in ballast water, which is disposed of in the oceans (Ruiz et al. 2000). Invasion is well documented for multicellular species and it is also possible that microbes could be invasive and that a successful invasion of bacteria could eradicate an endemic species. The following scenario, however, is more likely. As an invasive plant or animal species can replace another species, it can also replace the microorganisms associated with this species. To the best of our knowledge, there has as yet been no study of the way invasive species affect the composition and performance of the indigenous microbial communities.

Lake Vostok is an Antarctic lake covered with more than $3500 \mathrm{~m}$ of ice. It is estimated that it has been isolated from the rest of the world for about 20 million yr, time enough for a unique set of microorganisms to develop. It is thought that this lake, or at least the ice originating from this lake, contains endemic microorganisms (Karl et al. 1999, Priscu et al. 1999). The planned scientific investigation of Lake Vostok using drilling devices has raised considerable concern, since contaminating microorganisms introduced by the cooling fluids from the drilling devices could adapt to low temperatures and have a devastating effect on the indigenous microbes. Contamination of this lake with microorganisms might destroy the chance to investigate a restricted microbial community that has evolved over 20 million yr without external influences.

It has been estimated that a large proportion of the world's coral reefs are endangered and that bleaching, i.e. losses of zooxanthellae, is one of the main reasons for this. At high temperatures, bacteria such as Vibrio shiloi and $V$. coralilyticus can produce toxins, which cause bleaching, and this suggests a link between climate change and coral disease (Rosenberg \& BenHaim 2002). In bleached corals, the prokaryotic species composition is changed, as a result, for example, of increased mucus production. Climate change can also affect human health by influencing human pathogens, as has been demonstrated for cholera, for instance. The distribution and levels of zooplankton, which acts as a carrier or reservoir for the pathogen, are affected by climate change, and this has an effect on the spread of the disease (Colwell et al. 1998). Cholera is caused by the bacterium $V$. cholerae when it is associated with a temperate phage that carries the genes for the cholera toxin (Waldor \& Mekalanos 1996). Recent evidence suggests that antibiotic resistance of bacteria as a result of the use of antibiotics in fish farming can spread throughout the world within years (Sørum 2002). This might pose a threat to indigenous microorganisms as it could cause shifts in community composition, depending on the ability of different prokaryotic species for lateral gene transfer. It is difficult to assess whether or not the examples described here will result in losses of microbes; they indicate, however, that global change and anthropogenic effects may change the habitable landscape of microorganisms.

Ethical concerns about eradicating microorganisms have been raised. For example, a dispute arose when it was announced that stores of smallpox viruseswhich cause a disease that appears to have been eradicated - would be destroyed (Ogunseitan 2002). This would have been the first deliberate eradication of a microbial species by humans. The plan has since been dropped, since the arguments in favor of retaining and investigating the stored virus against the background of the potential rise of a similar or resurrection of the same smallpox virus from thawing plains in the Siberian tundra outweighed the arguments on the danger of an accidental infection of a person handling the virus and its potential in bioterrorism. However, plans do exist to eradicate diseases such as leprosy or polio, and considerable progress has been made here despite a number of drawbacks. Eradication of diseases also means eradication of microbial pathogens and represents attempts to deliberately remove life forms from this planet. It is not the intention of the authors to attempt to prevent this and risk human lives, or to argue for 'microbial rights' but we wish to point out that the complete eradication of a disease can also mean extinction of the pathogen.

The potential effect of (local) microbial extinctions for ecosystem functions is difficult to evaluate but will depend on the role of the microbes in the ecosystem. Studies addressing this problem are still rare, although this issue is now tackled in research on the way micro- 
bial diversity is related to ecosystem services (Bell et al. 2005). Such data suggest that high bacterial diversity sustains ecosystem functions and thus, if some phylotypes become locally extinct or greatly reduced in numbers, this could influence ecosystem functions. Losses of microbes represent lost genetic material, which is potentially useful in biotechnology and medicine. Losses of microbes in habitats such as Lake Vostok might deprive us of the possibility to learn more about the functioning and evolution of extreme microbial communities.

\section{THE STUDY OF ENDANGERED MICROBES}

Most of the scenarios presented above are quite speculative. The conditions and consequences of causes for extinction of microbes remain basically unknown. Clearly, more research is needed in this field. Research on endangered species is also research on the ecology of these species, in particular on their niche parameters as it is this which will determine their survival upon changes in their environment. We now have some tools at hand to begin investigations and more tools will be developed in the future. Knowledge of the ecology of microbes might also make it possible to develop isolation strategies. This has been shown for abundant but previously uncultured bacterial clades from marine and freshwater environments (Rappé et al. 2002, Hahn et al. 2003). Isolation of endangered microorganisms is a way to preserve such clades alive and at the same time have access to their genetic information. The ecology of non-isolated species can be studied using fluorescence in situ hybridization (FISH) probes obtained from environmental sequences as well as by a combination of such probes with microautoradiography, a combination which enables the detection of functions in uncultured microbes (Lee et al. 1999, Ouverney \& Fuhrman 1999, Cottrell \& Kirchman 2000). Because of the cultivation problem, it is necessary to use techniques such as sequencing for detection.

Some progress has been made in assessing changes in bacterial composition during faunal mass extinctions using lipid biomarkers (Xie et al. 2005). Such research might finally also make it possible to detect extinctions of bacteria from fossil records. However, these techniques are currently not species-specific and are therefore not further discussed here.

Major problems for the study of endangered microbes are the uncertainities with the species concept and the difficulties involved in determin- ing which species are endangered. There are no endangered species lists available for microorganisms, although the list of pathogens with the highest priority for eradication could be considered as such. Assessing microorganisms specific to endangered species could be a first step towards creating such a list. This means that we need species inventories of associated microbes for endangered species and species inventories of free-living microorganisms in as many environments as possible. Such inventories are needed to detect changes in the species diversity of microorganisms. Culture-independent techniques such as genetic fingerprints including sequencing, DNA microarrays and community genomics might be powerful tools which could be used to establish microbial species inventories (Table 2). The current enterprise of J. Craig Venter Institute's Sorcerer II expedition to 'sequence the ocean' will provide a valuable database for such inventories (Rusch et al. 2007). 454 sequencing, which has revealed a 'rare bacterial biosphere' (Sogin et al. 2006), is another potential technique.

For organisms larger than prokaryotes, such as protists, the situation is somewhat better. As these can be studied using microscopes, there is probably a great deal of information on species lists buried in old books and reports of oceanographic institutes. Such information might be used to find out whether there is evidence for species losses or declines. Limnological institutes might have similar data on other species. In general, an assessment of microbial biodiversity will increase our understanding of endangered microbial species. Obtaining comprehensive species inventories is a prerequisite for assessing potential changes in microbial communities, their long-term variability and the potential threat of extinction. It might also be useful to consider collecting the community genome and proteome of microorganisms from endangered areas. This would not protect the microbes, but would at least ensure that their genetic information is conserved.

Table 2. Methods of monitoring microbial diversity and its losses. FISH: fluorescence in situ hybridization

\begin{tabular}{|lll|}
\hline Method & Target & Use \\
\hline Isolation & Species/strains & Storage alive \\
Clone libraries & Ribosomal RNA & Species inventory \\
Fingerprints & Ribosomal RNA & Presence vs. absence \\
FISH & Ribosomal RNA & Quantification of types \\
MICRO-FISH & Ribosomal RNA; & Activity of types \\
& uptake systems & \\
Genomics & Genome & Genetic diversity of types \\
Metagenomics & Community genome & Genetic diversity of communities \\
Postgenomics & Community genome & Biodiversity of communities \\
& and proteome & \\
\hline
\end{tabular}


Many microbes can be stored in glycerin at $-80^{\circ} \mathrm{C}$ without losing their viability and in this way it might be possible to conserve part of the natural consortia alive. Billions of living microbial cells and their information encoded in the genome and proteome could be stored in a few small tubes per environment, so an average laboratory type $-80^{\circ} \mathrm{C}$ freezer could harbor the microbes of hundreds of environments.

In contrast to other species, most microbes probably do not suffer much from habitat fragmentation, since they need smaller habitats than larger species. Studying microbes during habitat fragmentation or in areas of changing habitat structure such as caused by agriculture, forestry and other human activities will increase our knowledge of the survival of microbes. An increasing amount of information is available on bacteria in soils subject to fertilization.

Overall, most free-living microbes do not seem to be threatened by extinction, although the number of threatened species might be higher than anticipated. Associated microbes, however, are an entirely different case, since these are-as long as they are specific to the respective plant or animal host-equally as threatened as their hosts are. Thus, extinction rates have to be reconsidered.

Research on endangered microbes is still in its infancy. We suggest that databases which include species inventories should be compiled so as to be able to monitor microorganism species losses; this would provide a means of predicting the threat of potential microbial eradication to humankind and to the Earth's ecosystems.

\section{SUMMARY}

It is not intuitively obvious that microbes can be endangered. The following points summarize the evidence and potential consequences of microbial extinction.

(1) Recent evidence suggests that both biogeography and endemicity exist for free-living microorganisms.

(2) Most free-living microorganisms are not endangered.

(3) Free-living endemic microorganisms are endangered to the same extent as their habitats.

(4) Local extinction of or a considerable reduction in the abundance of phylotypes could influence microbemediated ecosystem functions.

(5) Associated microbes (symbiotically or more indirectly) are endangered to the same extent as their hosts.

(6) For some pathogens, eradication, and thus extinction, is inevitable and for others it is pending.

(7) In environments such as Lake Vostok a direct anthropogenic influence could wipe out microbial species.
Acknowledgements. We thank Christian Sardet for coloring the TEM picture and John Dolan for improving the English. The comments of 3 reviewers improved the manuscript. This paper is part of the Network of Excellence MarBEF, specifically to the Responsive Mode Project (RMP) 'Microbial diversity and ecosystem functions: concepts, open questions and recommendations for integration of microbes into general ecological frameworks'.

\section{LITERATURE CITED}

Angly FE, Felts B, Breitbart M, Salamon P and 14 others (2006) The marine viromes of four oceanic regions. PLoS Biol 4:e368

Bell T, Newman JA, Silverman BW, Turner SL, Lilley AK (2005) The contribution of species richness and composition to bacterial services. Nature 436:1157-1160

Bourne DG, Munn CB (2005) Diversity of bacteria associated with the coral Pocillopora damicornis from the Great Barrier Reef. Environ Microbiol 7:1162-1174

Breitbart M, Salamon P, Andresen B, Mahaffy JM, Segall AM, Mead D, Azam F, Rohwer F (2002) Genomic analysis of uncultured marine viral communities. Proc Natl Acad Sci USA 99:14250-14255

Cho JC, Tiedje JM (2000) Biogeography and degree of endemicity of fluorescent Pseudomonas strains in soil. Appl Environ Microbiol 66:5448-5456

Cohan FM (2001) Bacterial species and speciation. Syst Biol 50:513-524

Colwell RR, Epstein PR, Gubler D, Maynard N, McMichael AJ, Patz JA, Sack RB, Shope R (1998) Climate change and human health. Science 279:968-969

Cottrell M, Kirchman D (2000) Natural assemblages of marine proteobacteria and members of the Cytophaga-Flavobacter cluster consuming low- and high-molecular-weight dissolved organic matter. Appl Environ Microbiol 66: 1692-1697

Cottrell MT, Suttle CA (1991) Wide-spread occurrence and clonal variation in viruses which cause lysis of a cosmopolitan, eukaryotic marine phytoplankter, Micromonas pusilla. Mar Ecol Prog Ser 78:1-9

de Wit R, Bouvier T (2006) 'Everything is everywhere, but, the environment selects'; what did Baas Becking and Beijerinck really say? Environ Microbiol 8:755-758

Dolan J (2005) Biogeography of aquatic microorganisms. Aquat Microb Ecol 41:39-48

Doolittle WF (1999) Phylogenetic classification and the universal tree. Science 284:2124-2129

Duckworth D (ed) (1987) History and basic properties of bacterial viruses. John Wiley \& Sons, New York

Emiliani C (1982) Extinctive evolution. Extinctive evolution and competitive evolution combined into a unified model of evolution. J Theor Biol 97:13-33

Emiliani E (1993) Viral extinctions in deep-sea species. Nature 366:217-218

Fenchel T (2005) Cosmopolitan microbes and their 'cryptic' species. Aquat Microb Ecol 41:49-54

Fierer N, Jackson RB (2006) The diversity and biogeography of soil bacterial communities. Proc Natl Acad Sci USA 103: 626-631

Finlay BJ, Fenchel T (1999) Divergent perspectives on protist species richness. Protist 150:229-233

Finlay BJ, Esteban GF, Fenchel T (1996) Global diversity and body size. Nature 383:132-133

Goffredi SK, Orphan VJ, Rouse GW, Jahnke L, Embaye T, Turk K, Lee R, Vrijenhoek RC (2005) Evolutionary innova- 
tion: a bone-eating marine symbiosis. Environ Microbiol 7: 1369-1378

Hahn MW, Lunsdorf $H$, Wu Q, Schauer M, Hofle MG, Boenigk J, Stadler P (2003) Isolation of novel ultramicrobacteria classified as actinobacteria from five freshwater habitats in Europe and Asia. Appl Environ Microbiol 69:1442-1451

Hendrix RW, Lawrence JG, Hatfull GF, Casjens S (2000) The origins and ongoing evolution of viruses. Trends Microbiol 8:504-508

Hughes JB, Hellmann JJ, Ricketts TH, Bohannan BJ (2001) Counting the uncountable: statistical approaches to estimating microbial diversity. Appl Environ Microbiol 67: 4399-4406

Karl D, Bird D, Björkman K, Houlihan T, Shackelford R, Tupas L (1999) Microorganisms in the accreted ice of Lake Vostok, Antarctica. Science 286:2144-2147

Karner MB, DeLong EF, Karl DM (2001) Archaeal dominance in the mesopelagic zone of the Pacific Ocean. Nature 409: 507-510

Katz LA, McManus GB, Snoeyenboes-West OLO, Griffin A, Prog K, Costas B, Foissner W (2005) Reframing the 'Everything is everywhere' debate: evidence for high gene flow and diversity in ciliate morphospecies. Aquat Microb Ecol 41:55-65

Lee N, Nielsen PH, Andreasen KH, Juretschko S, Nielsen JL, Schleifer KH, Wanger M (1999) Combination of fluorescent in situ hybridization and microautoradiography-a new tool for structure-function analyses in microbial ecology. Appl Environ Microbiol 65:1289-1297

Listgarten MA, Loomer PM (2003) Microbial identification in the management of periodontal diseases. A systematic review. Ann Periodontol 8:182-192

Lowe CD, Kemp SJ, Montagnes DJS (2005) An interdisciplinary approach to assess the functional diversity of free-living microscopic eukaryotes. Aquat Microb Ecol 41:67-77

Martin W (1999) Mosaic bacterial chromosomes: a challenge en route to a tree of genomes. Bioessays 21:99-104

Martiny JB, Bohannan BJ, Brown JH, Colwell RK and 12 others (2006) Microbial biogeography: putting microorganisms on the map. Nat Rev Microbiol 4:102-112

Mullins T, Britschgi T, Krest R, Giovannoni S (1995) Genetic comparisons reveal the same unknown bacterial lineages in Atlantic and Pacific bacterioplankton communities. Limnol Oceanogr 40:148-158

Oda Y, Star B, Huisman LA, Gottschal JC, Forney LJ (2003) Biogeography of the purple nonsulfur bacterium Rhodopseudomonas palustris. Appl Environ Microbiol 69: 5186-5191

Ogunseitan OA (2002) Global eradication of smallpox. In: Rasmussen K (ed) Great events of the twentieth century. Salem Press, Pasadena, CA, p 1974-1975

Ouverney CC, Fuhrman JA (1999) Combined microautoradiography-16S rRNA probe technique for determination of radioisotope uptake by specific microbial cell types in situ. Appl Environ Microbiol 65:1746-1752

Papke RT, Ward DM (2004) The importance of physical isolation to microbial diversification. FEMS Microbiol Ecol 48: 293-303

Pennisi E (1998) Genome data shake tree of life. Science 280: 672-674

Pernthaler J (2005) Predation on prokaryotes in the water column and its ecological implications. Nat Rev Microbiol 3:537-546

Pernthaler J, Amann R (2005) Fate of heterotrophic microbes in pelagic habitats: focus on populations. Microb Mol Biol Rev 69:440-461
Priscu JC, Adams EE, Lyons WB, Voytek MA and 8 others (1999) Geomicrobiology of subglacial ice above Lake Vostok, Antarctica. Science 286:2141-2144

Rappé MS, Connon SA, Vergin KL, Giovannoni SJ (2002) Cultivation of the ubiquitous SAR11 marine bacterioplankton clade. Nature 418:630-633

Reshef L, Koren O, Loya Y, Zilber-Rosenberg I, Rosenberg E (2006) The coral probiotic hypothesis. Environ Microbiol 8:2068-2073

Rohwer F, Breitbart M, Jara J, Azam F, Knowlton N (2001) Diversity of bacteria associated with the Caribbean coral Montastrea franksi. Coral Reefs 20:85-91

Rohwer F, Seguritan V, Azam F, Knowlton N (2002) Diversity and distribution of coral-associated bacteria. Mar Ecol Prog Ser 243:1-10

Rosenberg E, Ben-Haim Y (2002) Microbial diseases of corals and global warming. Environ Microbiol 4:318-326

Rosenberg E, Koren O, Reshef L, Efrony R, Zilber-Rosenberg I (2007) The role of microorganisms in coral health, disease and evolution. Nat Rev Microbiol 5:355-362

Rossello-Mora R, Amann R (2001) The species concept for prokaryotes. FEMS Microbiol Rev 25:39-67

Ruiz GM, Rawlings TK, Dobbs FC, Drake LA, Mullady T, Huq A, Colwell RR (2000) Global spread of microorganisms by ships. Nature 408:49-50

Rusch DB, Halpern AL, Sutton G, Heidelberg KB and 36 others (2007) The Sorcerer II global ocean sampling expedition: northwest Atlantic through eastern tropical Pacific. PLoS Biol 5:e77

Selje N, Simon M, Brinkhoff T (2004) A newly discovered Roseobacter cluster in temperate and polar oceans. Nature 427:445-448

Sogin ML, Morrison HG, Huber JA, Welch DM, Huse SM, Neal PR, Arrieta JM, Herndl GJ (2006) Microbial diversity in the deep sea and the underexplored 'rare biosphere'. Proc Natl Acad Sci USA 103:12115-12120

Sørum H (2002) Antibiotics in aquaculture - a dead end. In: Egli T, Zehnder A, Munzinger J (eds) Eau-water-acquawasser. 61st Annual Meeting of the Swiss Society for Microbiology, Lucerne, p 29

Suttle CA (2005) Viruses in the sea. Nature 437:356-361

Taylor MW, Schupp PJ, Dahllof I, Kjelleberg S, Steinberg PD (2004) Host specificity in marine sponge-associated bacteria, and potential implications for marine microbial diversity. Environ Microbiol 6:121-130

Taylor MW, Schupp PJ, de Nys R, Kjelleberg S, Steinberg PD (2005) Biogeography of bacteria associated with the marine sponge Cymbastela concentrica. Environ Microbiol 7:419-433

Torsvik V, Goksøyr J, Daae FL (1990) High diversity in DNA of soil bacteria. Appl Environ Microbiol 56:782-787

Torsvik V, Ovreas L, Thingstad TF (2002) Prokaryotic diversity-magnitude, dynamics, and controlling factors. Science 296:1064-1066

van Regenmortel MHV (1992) Concept of virus species. Biodivers Conserv 1:263-266

Venter JC, Remington K, Heidelberg JF, Halpern AL and 19 others (2004) Environmental genome shotgun sequencing of the Sargasso Sea. Science 304:66-74

Villarreal LP, DeFilippis VR (2000) A hypothesis for DNA viruses as the origin of eukaryotic replication proteins. J Virol 74:7079-7084

Villarreal LP, Defilippis VR, Gottlieb KA (2000) Acute and persistent viral life strategies and their relationship to emerging diseases. Virology 272:1-6

Waldor MK, Mekalanos JJ (1996) Lysogenic conversion by a filamentous phage encoding cholera toxin. Science 272: 
$1910-1914$

Weinbauer M (2004) Ecology of prokaryotic viruses. FEMS Microbiol Rev 28:127-181

Weinbauer M, Herndl G (2002) Viruses and heterotrophic microplankton. In: Duarte CM (ed) Marine Ecology Encyclopedia of life support systems (EOLSS), Vol. 2.27.3.4. Developed under the auspices of the UNESCO. EOLSS Publishers, Oxford (also available at: www.eolss. net)

Weinbauer MG, Rassoulzadegan F (2004) Are viruses driving microbial diversification and diversity? Environ Microbiol $6: 1-11$

Whitaker RJ, Grogan DW, Taylor JW (2003) Geographic barriers isolate endemic populations of hyperthermophilic archaea. Science 301:976-978

Whitman W, Coleman D, Wiebe W (1998) Prokaryotes: the unseen majority. Proc Natl Acad Sci USA 95:6578-6583

Editorial responsibility: Brendan Godley (Editor-in-Chief), University of Exeter, Cornwall Campus, UK
Xie S, Pancost RD, Yin H, Wang H, Evershed RP (2005) Two episodes of microbial change coupled with Permo/Triassic faunal mass extinction. Nature 434:494-497

Zhong Y, Chen F, Wilhelm S, Poorvin L, Hodson R (2002) Phylogenetic diversity of marine cyanophage isolates and natural virus communities as revealed by sequences of viral capsid assembly protein gene g20. Appl Environ Microbiol 68:1576-1584

Zubkov MV, Fuchs BM, Archer SD, Kiene RP, Amann R, Burkill PH (2001a) Linking the composition of bacterioplankton to rapid turnover of dissolved dimethylsulphoniopropionate in an algal bloom in the North Sea. Environ Microbiol 3:304-311

Zubkov MV, Fuchs BM, Burkill PH, Amann R (2001b) Comparison of cellular and biomass specific activities of dominant bacterioplankton groups in stratified waters of the Celtic Sea. Appl Environ Microbiol 67:5210-5218

Submitted: September 1, 2005; Accepted: July 10, 2007 Proofs received from author(s): August 2, 2007 